\title{
Post-Traumatic Stress Disorder among midwives after exposure to maternal death and stillbirth in Khomas Region of Namibia
}

\author{
Tuwilika Endjala*, Hans Justus Amukugo, Emma Maano Nghitanwa \\ School of Nursing, University of Namibia, Namibia
}

Received: May 16, 2021

DOI: $10.5430 / \mathrm{ijh} . v 7 \mathrm{n} 2 \mathrm{p} 7$
Accepted: July 6, 2021

URL: https://doi.org/10.5430/ijh.v7n2p7
Online Published: August 17, 2021

\begin{abstract}
Objective: Despite global efforts to decrease maternal death and stillbirths worldwide, maternal mortality rate and stillbirth remain high in the global south countries. These deaths often have immediate and long-lasting effects on midwives who care for these women.

Methods: This paper explores the effects of maternal death and stillbirth on midwives in Namibia. A qualitative approach was adopted using a descriptive, exploratory and contextual design. The objective of this study was to explore the Post-Traumatic Stress Disorder (PTSD) related feelings among midwives after exposure to maternal death and stillbirth. Data was collected using Focus Group Discussions (FGD) and individual interviews. Four FGDs and four individual interviews were conducted with midwives from two state hospitals in Windhoek. Midwives were purposively selected, and a total of 29 midwives participated in the study. Individual interviews and FGDs were audiotaped and transcribed verbatim. Data were analysed using content analysis and coded using Tech's steps of open-coding.

Results: The researcher identified one central theme with six sub-themes. The study showed that the midwives experienced PTSD related feelings such as insomnia and nightmares, recollection of the event (flashbacks), sense of self-blame, guilt, anger, shame, and being haunted/tormented.

Conclusions: It is concluded that maternal death and fresh stillbirth can lead to PTSD effects on midwives, hence addressing these challenges. Therefore, the researchers recommend that hospitals in the Khomas Region develop and implement the wellness programmes in the workplace, such as the Employee Assistance Programme, to support midwives who experienced these traumatic events to prevent and manage these effects in the future. Equally, further research is needed to evaluate the impact of the wellness programme on midwives who experienced MDs and FSBs in Namibia.
\end{abstract}

Key Words: Midwives, Maternal death, Stillbirths, Post-Traumatic Stress Disorder, Support

\section{INTRODUCTION}

Maternal mortality and stillbirth remain major public health problems globally, especially in low-income countries. ${ }^{[1]}$ About 256,000 mothers die globally per year due to pregnancy and postpartum complications, and more than 2.6 million stillbirths occur, with half of these stillbirths occurring before a woman goes into labour. ${ }^{[1]}$ Maternal deaths and stillbirths are therefore prioritised as one of the sustainable development goals of the United Nations. Although the global Maternal Mortality Ratio (MMR) had been reduced

* Correspondence: Tuwilika Endjala; Email: tendjala@unam.na; Address: School of Nursing, University of Namibia, Namibia. 
in high-income countries, developing countries remain with a high burden of MDs. Maternal mortality was reduced by nearly half in 2015 than the 1990 rate; however, significant discrepancies remain amongst regions. ${ }^{[2]}$

Africa has recorded the highest MMR, with the sub-Saharan Africa region alone recording an increased number of 546 accounts for $62 \%$ of global deaths in 2015. ${ }^{[3]}$ Nevertheless, close to 13,000 mothers still die daily in sub-Saharan Africa due to poor health care systems. ${ }^{[4]}$ These deaths are believed to leave midwives with effects that could be prevented if individual African countries follow correct measures. ${ }^{[5]}$ Equally, Blencowe et al. ${ }^{[6]}$ report that in 2016 sub-Saharan Africa accounted for the highest stillbirth rate of 28.7 per 1,000 total births and an estimated 1.06 million stillbirths. As a result, the Sub-Saharan region has since implemented Sustainable Development Goals since many countries have not reached the millennium development goals.

In Namibia, MDs account for $9 \%$ of all deaths among women aged 15-49. ${ }^{[7]}$ According to the 2013 Namibia Demographic Health Survey (NDHS), MMR has been increasing, with the statistics showing the prevalence figures standing at $249 / 100,000$ in 1992, 271/100,000 in 2000, 449/100,000 in 2006/2007. ${ }^{[7]}$ Although there was a slight decrease in 2013 to $385 / 100,000$ the difference is insignificant as the MMR remained higher in Namibia at 265 per 1,000 live births in 2015. ${ }^{[8]}$ Thus, Namibia has failed to reach the previous Millennium Development Goals (MDG) target of achieving a reduction of MMR to 56/100,000 by 2015. ${ }^{[4]}$ The lifetime MD risk in Namibia is at $1.4 \%$, which translates to the risk ratio of 1:71, which is higher than an average ratio of $1: 160$ for countries in the global south. ${ }^{[8]}$ In 2015, the stillbirth rate in Namibia stood at 17 per 1,000 total births. ${ }^{[8]}$ This 2015 rate is higher than the target of 10 deaths per 1,000 births. ${ }^{[8]}$ Employers should take measures to address these deaths as nothing can remove the pain and grief that parents and midwives go through after an MD and SB.

It is, however, vital to note that at the site where this study was conducted, all facilities are referral hospitals and offer Comprehensive Emergency Obstetric and Newborn Care (CEmONC). Notably, all eight signal functions are performed in these facilities. Furthermore, it is in these facilities where deliveries are performed and where women are attended to by midwives. If there are complications that midwives with undergraduate qualifications cannot handle, the doctors are always within reach to manage such delivery complications, as there were no advanced midwives during the study.

Post-Traumatic Stress Disorder (PTSD) usually develops when an individual is exposed to frequent distressing and helplessness due to traumatic events such as maternal deaths and stillbirth. ${ }^{[9]}$ PTSD is a clinically substantial distressing situation in an individual that reduces social interaction, work capability and self-destruction or violence to others. ${ }^{[10]}$ After the traumatic event, the victims relive the trauma through disturbing memories and nightmares and develop a numbing of emotional responsiveness and increased arousal and alertness. ${ }^{[11,12]}$ Health care professionals, especially midwives and obstetricians who witness sudden traumatic events such as MDs and perinatal deaths, are at a high risk of developing PTSD. ${ }^{[13-15]}$ Signs of PSTD include difficulties in sleeping, nightmare, flashbacks, guilt, avoidance of reminders, feeling isolated from supporters, anger and helplessness. ${ }^{[14,16]}$ Nevertheless, in their study, Sheen et al. ${ }^{[14]}$ did not identify previous life trauma as a predictor of post-traumatic syndrome among midwives.

\subsection{Problem statement}

This study was necessitated by reports of the high number of MD at $27 \%$ (32) out of 119 deaths countrywide and stillbirths at $19.2 \%$ (608) out of 3,169 deaths countrywide that midwives experienced in the Khomas Region in 2018. [17] The researchers, as midwives, observed that no special attention is given to this vital area of employees' health and wellness in Namibia. Calvert and Benn ${ }^{[9,18]}$ identified that MD and stillbirth affect the midwives' emotions. This can result from the reality in midwifery as midwives usually care for healthier pregnant women and would expect good pregnancy outcome. Sadly, MD and stillbirth are sudden incidents and leave midwives with feelings of failure. ${ }^{[20]}$ Furthermore, in their study, Schroder et al. ${ }^{[19]}$ found experiences such as shame, fear, trauma, saddening, sense of empathy, anger, guilt, emotional exhaustion as some of the PTSD effects that midwives experienced after adverse events such as MD and stillbirth. In Ghana, for instance, midwives were left with feelings of helplessness, grief and emotional stress after maternal death. ${ }^{[5]}$

The exact effects and extent of these deaths on the midwives in the Khomas Region are unknown as no known scientific studies have been conducted. The absence of evidence-based wellness programme to support midwives in the country could exacerbate the psychological effects that may be experienced. Given the impacts that MD and stillbirths have on midwives in other countries, the researchers noted the need to explore the effects of MD and stillbirth on midwives in the Khomas Region.

\subsection{Purpose and objectives of the study}

The purpose of the study was to explore the effects that maternal death and stillbirth have on midwives in Namibia. The 
study objective was to discover and describe the experience of midwives with regards to maternal deaths and stillbirths.

\section{RESEARCH DESIGN AND METHODS}

\subsection{Design}

The researchers used a qualitative approach using a descriptive exploratory design. This design is appropriate as it allows to study participants' lived experience in their working environment. This design assists the researchers to gain meaningful information and insight into the subject under investigation. $^{[21]}$

\subsection{Study population and sampling}

The population for this study consisted of enrolled, registered and senior registered midwives in the Khomas Region with a total population of 169 midwives and eight senior registered midwives. The study was conducted at two-state referral hospitals in Windhoek, and non-probability purposive sampling was used until saturation was reached.

\subsection{Data collection}

A pilot study was conducted with one FGD and two midwives at a different intermediate hospital in another region. A total of four FGD and four individual interviews with midwives working in other maternity wards were conducted. Focus Groups Discussions consisted of participants between six and seven $(n=6-7)$. During this study, midwives were approached during their shift breaks or times when they were not involved in active patient care on day and evening shifts and during their off days. The researchers audiotaped interviews and FGDs sessions as preferred data collection methods, which lasted for about 35-60 minutes. Furthermore, the researchers have used interview and FGD guides during the study. Accordingly, data collection and analysis for this study was done between September and October 2019.

\subsection{Data analysis}

Data analysis was conducted concurrently with data collection, and this assisted the researchers in picking up data saturation. Data were transcribed verbatim before the analysis process, and the data analysis followed interpretive analysis steps of qualitative data according to Creswell, ${ }^{[22]}$ as outlined below:

Reading the transcribed data to get the general sense and the meaning thereof and to understand what participants would have stated; coding to extract categories and subcategories according to Creswell's ${ }^{[22]}$ eight Tesch's descriptive steps of data analysis; development of themes and sub-themes from the identified codes; the interpretation of the themes was given to the developed themes, which was done narratively.

\subsection{Measures to ensure trustworthiness}

Trustworthiness was applied during the study according to the criteria of Bryman ${ }^{[23-25]}$ as follows: Credibility was ensured through the use of source triangulation of data (FGD, in-depth interviews and field notes) to enhance the data collection. Verbatim transcription and literature control were also used to develop themes and confirm the data during interpretations. An audio recorder was used during data collection to ensure referential adequacy. A transcription of data verbatim followed this to ensure that no data would be lost during analysis. Transferability was ensured by maintaining the correct sample (midwives and senior midwives), and only participants who met the inclusion criteria were selected. A thick description of data was provided to convey the findings, and purposive sampling was maintained and chosen participants until data saturation to ensure transferability. Dependability was ensured by carrying an inquiry audit during data collection, and transcripts were verified for quality control. Participants were given a summary after each interview to evaluate the researcher's understanding of them, ensuring confirmability. To maintain authenticity, the participants' findings were illustrated in direct quotations to ensure that the participants' stories' meanings are not distorted.

\subsection{Ethical considerations}

The University of Namibia's Human Research Ethics Committee (HREC) and the Ministry of Health and Social Services approved the research before collecting data (Ref no: OSHC/484/2018). Participants were all above 18 years old, and written informed consents were obtained before data collection. Participation was voluntary, and the researchers ensured privacy and confidentiality of the participants' information by treating participants with respect and dignity. Thus, the FGD and individual interviews used for data collection were held privately to ensure the privacy and dignity of the participants. The voice recordings and transcriptions of the data set were passwords protected. Measures to abate psychological discomfort (harm) were put in place should it happen. Thus, arrangements were made with the social workers at the study sites. To ensure justice, participants were treated with fairness during all stages of the research process.

\section{Results}

\subsection{Demographic characteristics}

A total of 29 participants took part in the study. The age of the participants ranged from 23-55 years, and only 8 participants who participated in the FGD are above 35 years. For individual interviews, the youngest senior midwife was 40 years while the oldest was 50 years and all participants were females. All midwives had a minimum of three years 
of work experience, and they all experienced maternal deaths and Fresh Stillbirths (FSB) (see Table 1).

Table 1. Demographic data of participants

\begin{tabular}{lll}
\hline Items & Age & Number of participants \\
\hline FGDs & & \\
FGD 1 & 25, 37, 59, 55, 27, 36 & 6 \\
FGD 2 & 23, 26, 28, 25, 34, 24, 40 & 7 \\
FGD 3 & $45,52,30,23,26,33$ & 6 \\
FGD 4 & $28,26,47,54,30,27$ & 6 \\
Interviews & & \\
Interview 1 & 40 & 1 \\
Interview 2 & 50 & 1 \\
Interview 3 & 48 & 1 \\
Interview 4 & 47 & 1 \\
\hline
\end{tabular}

\subsection{Post-Traumatic Stress Disorder related feelings}

In this study, it was found that midwives experienced PTSD related feelings and signs such as insomnia and nightmares, recollection of event (flashbacks), sense of self-blame and sense of guilt, shame, anger and haunted/tormented as described as sub-themes below:

\subsubsection{Insomnia and nightmares}

The findings revealed that midwives suffered from difficulties in sleeping as a result of death events, as expressed in the following verbatim statements:

It touched me so bad, and I couldn't sleep for days. Arriving home, I remember that night I did not sleep, not well, and I could hear all the dramas that happened during the event in my mind. [FGD2 P\#1]

Since that event happen, I could not even sleep, and I am now living with those post-traumatic stress symptoms that I had to seek for professional assistance. [FGD 4 P\#4]

Furthermore, it is evident from the study that some midwives were living with nightmares as a result of MDs and FSBs that they have experienced. The response underneath indicated the views of these midwives:

When I went home, I couldn't sleep for nights. I was getting nightmares and seeing the mother bringing her baby that is stillborn to me. [FGD4 P\#3]

I started getting bad dreams of her [deceased] angry at me and wanting to beat me. I couldn't sleep for weeks. [FGD 4 P\#5]
Some midwives who were pregnant during the study had nightmares after losing their babies, as revealed in the quote below:

Since I was also pregnant that time, I started having dreams of my baby dying during the birth process. [FGD2 $\mathrm{P} \#$ 4]

\subsubsection{Recollection of event (flashbacks)}

The experience of flashbacks can include moments of happiness, excitement, sadness or many other emotions. In this study, both senior and ward level midwives experienced intrusion repetition or a recollection of events in the form of images. Some midwives reported auditory senses where they started hearing voices of the deceased (e.g., how the deceased used to speak or make jokes) in cases of MDs. This is evident from the quotes below:

I was always seeing her sitting at the entrance of the ward after she died. It's really a bad thing because you stay for days and months still thinking about it. [I \#3]

Every time I come to work and go in that room, I was getting the whole recollection of the event, and the face of the mother was always in my mind, and all your imagination run to that incident. [FGD2 P\#3]

Over the years, a person who died even in 2012 you can recall even by name. It's a person you don't know, but it is just in you. It's really difficult to to to come to terms with but you try to cope, but it's not easy, and you know, it's a memory, you carry it, you are re re re what reliving the whole experience especially for the next couple of years. [I \#4]

Every time I go in that room, the event come straight in my mind, and I worked with fear every time I go in that room after the incident, especially at night. I use to hear her voice talking to me as she liked jokes since she was a lovely person. [FGD3 P\#4]

\subsubsection{Sense of self-blame and sense of guilt}

Self-blame and a sense of guilt can give midwives the feeling that they did not provide the care expected of them to their clients. In this study, the participants used self-blame and guilt interchangeably to mean one thing. Findings showed that most midwives in the study were found to have blamed themselves after especially after the avoidable MD and FSB. For some, this was so because of the bond that they have developed with the women. The following statements demonstrated this:

ISSN 2377-7338 E-ISSN 2377-7346 
I was so bad because I was so used to the patient, and I developed a good bond with her. I was feeling that aah I am just killing people and I am supposed to be saving their lives. Ok, after a maternal death, I felt like I killed someone. Some of these deaths are avoidable, such as PPH that killed this women. [FGD1 P\#4]

I was feeling that aah I am just killing people and I am supposed to be saving their lives. Ok, after a maternal death I felt like I killed someone. (FGD2 P\#4)

I sit with regrets, and you will be like perhaps I am the one who caused the death. This is the same feeling that you get even in cases where you have done your best. [FGD3 P\#6]

I kept blaming myself even though the patient was a referral, she was stabilising, and she improved significantly during my care. I just felt I failed the women, that women couldn't have lose her baby. I sometimes feel that I lack the necessary expertise that's why I want to go and do advance midwifery so that I can manage the complications better like shoulder dystocia that killed this baby. [I\#3]

Some participants further felt guilty after the incidents of deaths as reported in the statements below:

Eish, I feel sorry for the patient, and for me, I feel guilty; you feel like you have failed the mission that you suppose to do because my aim is to preserve life and not to let people die. [I\#3]

You feel like why do I have to blame myself if I have tried all I could but if you know a case has happened and then you think you didn't try that much there you really feel guilty even for years, especially if it is a maternal death. It really affects you negatively. [FGD2 P\#4]

I was feeling so guilty that maybe the mother was not advised well at ANC where I also work. [FGD2 P\#2]

\subsubsection{Anger}

In the current study, it was evident that some participants felt angry after FSBs and MDs. Some midwives raised concerns of anger after the death cases because of the other circumstances regarding the deceased such as incest among teenagers, as illustrated in the participants' views below:

You will get all the question of, sometimes it make you want to kill someone. You are 13, and you are pregnant, and the father of the stillborn is your family member (uncle). Look, the person who brought that patient is the one telling you she was staying with uncle blah blah blah. At the time, you want to be a police officer and lock someone up. I was angry to the point that I want to explode because of the situation at hand. [FGD2 P\#6]

\subsubsection{Ashamed}

One participant in the study felt ashamed after an FSB as they did not know how to face the family. This is demonstrated in the following quotes:

I did not want even to look at the family because I didn't know what to tell them. I was so ashamed, and I cried so much that day that I had to be sent home by the doctor and the supervisor at that time. [I\#4]

....it make me ashamed, number 1 it make me ashamed, you feel like you are not a midwife. [I\#4]

\subsubsection{Haunted/tormented}

The state of being haunted is a feeling associated with mental anguish. ${ }^{[1]}$ Some participants felt tormented when they went back to work after a death event. It is expressed in the following excerpt:

Up until today, it haunts me. [FGD2 P\#5]

I felt that something was tormenting me in that room when I came back to work. [FGD3 P\#3]

\section{Discussion}

Midwives in this study reported insomnia after experiencing an MD and FSB. A study conducted in Israel among midwives and a scoping review in Australia affirms the above findings as both reports that midwives had sleeping problems after traumatic death events. ${ }^{[15,16,26]}$ On the contrary, burnout was found to be one of the highest contributing factors among midwives working in perinatal wards. ${ }^{[27,28]}$ Dartey et al. ${ }^{[5]}$ maintain that extended periods of lack of sleep among midwives can lead to poor mental states and, eventually, the poor quality of work life.

The American Psychiatric Association ${ }^{[10]}$ defines a nightmare as a disturbing dream linked to undesirable feelings, such as anxiety or terror, that awakens people. Nightmares are generally predominant in children; however, they can occur at any stage of a person's life. In adults, occasional nightmares are ordinarily nothing to worry about, but they become abnormal and worrisome after a traumatic event, as 
reported in this study. Cohen et al. ${ }^{[26]}$ document nightmares amongst midwives and obstetricians who have experience maternal deaths.

While pregnant, working in maternity units was found to be one of the stimulants that incite fear and feelings of distress. ${ }^{[29]}$ This study noted that some pregnant midwives who experienced MDs and FSBs had similar views as they shared terrible dreams of their babies passing during the birth process. Overall, midwives were found to experience sleeping disorders after traumatic events. Given these findings, midwives need support, such as psychological counselling, to assist with the sleeping disorders that may affect their ability to concentrate and work performance. ${ }^{[30]}$

As explained in Horowitz's ${ }^{[31]}$ theory, intrusion repetition is defined as recollections of a traumatic event that has occurred unexpectedly in an individual's mind. A flashback or memory of events is further described as an involuntary, sudden reliving of a psychologically positive or negative past experience of an event categorised as disruptive. ${ }^{[10]}$ It includes imaginations, behaviour or emotions and can happen when an individual is awake or asleep as a dream. Wahlberg et al. ${ }^{[13,15,32]}$ found similar results where midwives re-experienced a past event. Therefore, it is argued that trauma memories might never be "erased" and are expected to re-emerge when the midwife is faced with a similar stressful event. ${ }^{[13]}$

Another finding that midwives in this study highly reported is self-blame. Dartey et al. ${ }^{[22]}$ concur with this study's results in their observation that midwives blamed themselves over the deaths of their clients because the mothers were not sick but only going through the changes of pregnancy. It may cause frustration among midwives, and they can develop feelings that they have failed in their duty to render care. It could therefore contribute to social isolation, unhappiness and lower the quality of life of midwives. A survey conducted by Sheen et al. ${ }^{[33]}$ concludes that traumatic events had a common theme of generating feelings of responsibility and blame among midwives in Liverpool.

Wahlberg et al. ${ }^{[15]}$ corroborate with the current study's findings that most health care professionals who experience death cases, especially maternal and perinatal deaths, feel guilty. It results in psychological difficulties among midwives, as observed in this study. Other studies assert that most of the participants expressed feelings of self-blame and guilt. ${ }^{[11,12]}$ This led the midwives to question their action wonder they could have contributed to the death event. ${ }^{[34]}$ The feeling of guilt is described as a lasting emotion that often remains unresolved and could lead to being incomplete. It may, however, lead to midwives initiating perfectionist behaviour that would strengthen guilt. ${ }^{[34,35]}$ It is therefore worth noting that most midwives in the study acknowledged the feeling of not doing their work satisfactorily, hence the guilt.

In other studies, it was noted that peritraumatic distress in the midwives had resulted in anger. ${ }^{[11,12]}$ This feeling of anger could be attributed to the sense of failure to save the women and their foetus among midwives, as stated in the above findings. Therefore, midwives must be allowed to express themselves after a deadly incident to minimise their anger. Anger is a feeling of displeasure at what would have happened. ${ }^{[11]}$

Cauldwell et al. ${ }^{[19,27,34]}$ corroborate this study's findings in the observation that maternal death has a notable lasting impact on midwives as they are left with feelings of grief and shame that they are hesitant to verbalise. As a result, some midwives may be suffering in silence as they are ashamed of talking about their experiences of the death event. This may result in a decrease in work expectation, as observed in New Zealand and Switzerland. ${ }^{[36,37]}$ Therefore, positive attitudes among midwives should be encouraged after an MD and FSB avoid the above-explained feelings.

Midwives who develop haunted feelings can experience lower productivity levels as they fear the unknown and feel that the deceased is after them. This is believed to be expected after an MD and then FSB. This might be because there is usually a minimal bond between the midwife and the baby in FSB cases, unlike the MDs where the mother may have been in the ward for some days, and a relationship is developed. The mother is an adult who can communicate. Austin ${ }^{[1,27]}$ concurs with the above findings as noted in the observation that midwives in their study experienced the tormented feeling after death events. This, however, may lead to poor quality of work-life for the midwives.

\section{Conclusion}

This study was the known first of its kind in Namibia to reveal the PTSD effects among midwives after exposure to traumatic events such as MD and FSB in their work environment. It included feelings such as insomnia and nightmares, recollection of event (flashbacks), sense of self-blame and sense of guilt, shame, anger, and haunted/tormented.

\subsection{Recommendations}

Recommendations for practice, education and future research are made based on the findings of the study. The researchers recommend that the MoHSS provides formal support by creating a safe and supportive work environment for midwives to practise. It will assist in retaining midwives in their profession. An Employee Assistance Programme should be 
developed and implemented in the clinical practice to offer assistance to midwives affected by MD and FSB, especially on coping with the trauma and debriefing sessions. Moreover, other strategies that can be used to improve PTSD should include the following: cognitive behavioural and processing therapy; cognitive therapy; prolonged exposure; positive ways of coping such as learning about trauma, practice relaxation techniques and joining a support group. ${ }^{[13,37]}$ At the individual level, support can be provided informally by colleagues, families and friends. The formation of social groups where midwives can talk informally on issues affecting them at work is also recommended. In addition, there is a need for professional bodies to support midwives and provide Continuing Professional Development (CPD) activities related to the well-being of midwives and not simply on how to care for women. Further similar research needs to be conducted in other regions of the country, predominantly rural

\section{REFERENCES}

[1] United Nations International Children's Emergency Fund. Ending preventable newborn deaths and stillbirths by 2020: Moving faster towards high-quality universal health coverage in 2020-2025. Geneva, Switzerland: United Nations International Children's Emergency Fund. 2020.

[2] Alkema L, Chou D, Hogan D, et al. Global, regional, and national levels and trends in maternal mortality between 1990 and 2015, with scenario-based projections to 2030: a systematic analysis by the UN Maternal Mortality Estimation Inter-Agency Group. Lancet. 2016; 30(387): 462-74. https://doi.org/10.1016/S0140-6736(15 ) 00838-7

[3] Heemelaar S, Josef M, Diener Z, et al. Maternal near-miss surveillance, Namibia. Bulletin of World Health Organization. 2020; 98 : 548-557. PMid:32773900. https://doi.org/10.2471/BLT. 20 .251371

[4] World Health Organization. Namibia Biennial Report 2016 - 2017. Geneva, Switzerland. 2018.

[5] Dartey AF, Phuma-Ngaiyaye E, Phetlhu D. Effects of Death as a Unique Experience among Midwives in the Ashanti Region of Ghana. International Journal of Health Science. 2017; 7(12): 1587-167. Available from: www.ijhsr.org

[6] Blencowe H, Cousens S, Jasper FB, et al. National, regional, and worldwide estimates of stillbirth rates in 2015, with trends from 2000: A systematic analysis. Lancet Glob Heal [Internet]. 2016; 4(2): e98108. https://doi.org/10.1016/S2214-109X (15) 00275-2

[7] Ministry of Health and Social Services \& ICF International. The Namibian Demographic and Health Survey 2013. Windhoek: Ministry of Health and Social Services; 2014.

[8] Ministry of health and social services. Report on maternal, perinatal and neonatal death reviews April 2010-March 2016. Windhoek: Ministry of health and social services; 2016.

[9] Barlow D, Durand VM, du Plessis LM, et al. Abnormal psychology: An integrative approach. $1^{s t}$ South African ed. Australia: Cengage Learning; 2017.

Published by Sciedu Press and semi-rural areas and in the private sector, to compare.

\subsection{Limitations of the study}

Even though the study was successful, there were some limitations in the research process. The main limitation was that this study was only conducted in one region of Namibia and at public hospitals; thus, the findings cannot be generalised as views of all midwives in the country. Another limitation relates to the limited literature on the topic on the African continent, especially on SADC and Namibia in particular.

\section{ACKNOWLEDGEMENTS}

The researchers are very grateful to the midwives who participated in the study. This study was self-funded by the authors.

\section{CONFLicts OF INTEREST Disclosure}

The authors declare no conflicts of interest.
[10] American Psychiatric Association. Diagnostic and statistical manual of mental disorders $5^{\text {th }}$ ed. Arlington: American Psychiatric Association. 2013. https://doi.org/10.1176/appi.books. 97808 90425596

[11] Leinweber J, Creedy DK, Rowe H, et al. Responses to birth trauma and prevalence of post-traumatic stress among Australian midwives. Women and Birth. 2017; 30(1): 40-45. PMid:27425165. https://doi.org/10.1016/j.wombi.2016.06.006

[12] Toohill J, Fenwick J, Sidebotham M, et al. Trauma and fear in Australian midwives. Women and Birth. 2018; 32(1): 64-71. PMid:29759933. https://doi.org/10.1016/j. wombi.2018.0 4.003

[13] Leinweber J, Creedy DK, Rowe H, et al. A socioecological model of post-traumatic stress among Australian midwives. Midwifery. 2017; 45: 7-13. PMid:27960122. https://doi.org/10.1016/j.midw .2016 .12 .001

[14] Sheen K, Spiby H, Slab P. Exposure to traumatic perinatal experiences and post-traumatic stress symptoms in midwives: prevalence and association with burnout. International Journal of Nursing Studies. 2015; 52: 578-587. PMid:25561076. https://doi.org/10.1 016/j.ijnurstu. 2014.11.006

[15] Wahlberg AS, Johannesson M, Hallberg G, et al. Post-traumatic stress symptoms in Swedish obstetricians and midwives after severe obstetric events: a cross-sectional retrospective survey. An International Journal of Obstetrics and Gynaecology. 2017; 124(8): 1264-1271. PMid:27562912. https ://doi .org/10.1111/1471-0528.1425 9

[16] Cohen R, Leykin D, Golan-Hadari D, et al. Exposure to traumatic events at work, post-traumatic symptoms and professional quality of life among midwives. Midwifery. 2017; 5: 1-8. PMid:28347853. https://doi.org/10.1016/j.midw.2017.03.009

[17] Ministry of health and social services. Report on maternal, perinatal and neonatal death reviews. Windhoek: Ministry of Health and Social Services; 2018. 
[18] Calvert I, Benn C. Trauma and the effects on the midwife. International Journal of Childbirth. 2015; (2): 100-112. https://doi.or $\mathrm{g} / 10.1891 / 2156-5287.5 .2 .100$

[19] Schroder K, Larsen PV, Jorgensen JS, et al. Psychosocial health and well-being among obstetricians and midwives involved in traumatic childbirth. Midwifery. 2016; 42: 45-53. PMid:27540830. https://doi.org/10.1016/j.midw.2016.07.013

[20] Young CM, Smythe L, McraCouper J. Burnout: Lessons from the lived experience of case loading midwives. International Journal of Childbirth. 2015; 5(3): 154-165. https ://doi.org/10.1891/21 $56-5287 \cdot 5 \cdot 3 \cdot 154$

[21] Creswell JW, Creswell JD. Research design: Qualitative, Quantitative and mixed methods approaches. $5^{\text {th }}$ ed. London: SAGE; 2018.

[22] Creswell JW. Research Design. $4^{\text {th }}$ ed. London: SAGE; 2014.

[23] Bryman A. Social research methods. $5^{\text {th }}$ ed. New York: Oxford University Press; 2016.

[24] Creswell JW, Creswell JD. Research design: Qualitative, Quantitative and mixed methods approaches. $5^{\text {th }}$ ed. London: SAGE; 2018.

[25] Denzin NK, Lincoln YS. The Sage handbook of qualitative research. $5^{t h}$ ed. Thousand Oaks: SAGE; 2018.

[26] Alexander CR, Bogossian F. Midwives and clinical investigation: A review of the literature. Women and Birth. 2018; 31(6): 442-452. PMid:29525321. https://doi.org/10.1016/j.wombi.2018.0 2.003

[27] Austin D. Facilitating health professional well-being following critical incidents: An action research study. [Unpublished $\mathrm{PhD}$ thesis on the Internet]. Auckland: Auckland University of Technology; 2017 cited 2020 January 24. Available from: http: //hdl . handle.net /10292/10947

[28] Fenwick J, Sidebotham M, Gamble J, et al. The emotional and professional well-being of Australian midwives: A comparison between those providing continuity of midwifery care and those not providing continuity. Women and Birth. 2018; 31(1): 38-43. PMid:28697882. https://doi.org/10.1016/j.wombi.2017.06.013
[29] Anderson FWJ, Johnson TRB, de Vries R. Global Health Ethics: The Case of Maternal and Neonatal Survival. Best Practice and Research: Clinical Obstetrics and Gynaecology. 2017; 43: 125-135. PMid:28262553. https ://doi.org/10.1016/j.bpobgyn. 2017 .02 .003

[30] Dartey AF, Phuma-Ngaiyaye E. Physical Effects of Maternal Deaths on Midwives' Health: A Qualitative Approach. Hindawi Journal of Pregnancy. 2020; 1-6. PMid:32308995. https ://doi.org/10.1 $155 / 2020 / 2606798$

[31] Horowitz MJ. Stress response syndrome. $2^{\text {nd }}$ ed. Northvale, New Jersey: Jason Aronson; 1986.

[32] Polit DF, Beck CT. Nursing Research: Generating and assessing evidence for nursing practice. $9^{\text {th }}$ ed. Philadelphia: Lippincott; 2018.

[33] Sheen K, Spiby H, Slade P. The experience and impact of traumatic perinatal event experiences in midwives: A qualitative investigation. International Journal of Nursing Studies. 2016; 53: 61-72. PMid:26546399. https://doi.org/10.1016/j.ijnurstu. 201 5.10 .003

[34] Cauldwell M, Chappell LC, Murtagh G, et al. Learning about maternal death and grief in the profession: A pilot qualitative study. Acta Obstetricia et Gynecologica Scandinavica. 2015; 94(12): 1346-1353. PMid:26332761. https ://doi.org/10.1111/aogs . 12760

[35] Wallbank S, Robertson N. Midwife and nurse responses to miscarriage, stillbirth and neonatal death: A critical review of qualitative research International Journal of Nursing Studies Predictors of staff distress in response to professionally experienced miscarriage, stillbirth. International Journal of Nursing Studies. 2016; 50(8): 1090-1097. PMid:23312617. https://doi.org/10.1016/j.ijnurstu. 201 2.11.022

[36] Jones K, Smythe L. The impact on midwives of their first stillbirth. New Zealand. College of Midwives Journal. 2015; 51: 17-22. https://doi.org/10.12784/nzcomjn151.2015.3.17-22

[37] Kleim B, Bingisser MB, Bingisser R, et al. Frozen moments: Flashback memories of critical incidents in emergency personnel. Brain and Behavior. 2015; 5(7): 1-8. PMid:26221567. https://doi .or g/10.1002/brb3. 325 